\title{
IMPACT OF FERMENTING AGENTS ON MARKETED PATENT PROPRIETARY FORMULATION ASHWAGANDHA KALPA
}

\author{
AMBIKA THAKUR ${ }^{1}$, RENUKA THAKUR ${ }^{2}$, DILEEP SINGH BAGHEL ${ }^{1 *}$ \\ ${ }^{1}$ Department of Ayurvedic Pharmacy, School of Pharmaceutical Sciences, Lovely Professional University, Punjab, India. ${ }^{2}$ Baijnath R\&D Lab., \\ Paprola, Himachal Pradesh, India. Email: baghel_12@rediffmail.com
}

Received: 14 July 2017, Revised and Accepted: 25 July 2017

\section{ABSTRACT}

Objective: The present work is aimed to formulate Ashwagandha kalpa and evaluate the impact of fermenting agent.

Methods: A. kalpa is a marketed patent proprietary Ayurvedic product prepared by adopting the Ayurvedic principles of madya sandhana and it belongs to the class of formulations known as Sandhana kalpana. It is given to the patients suffering from hypertension, insomnia, paralysis, loss of concentration, etc. In the preparation of madya sandhana, the sandhana dravya (fermenting agents) play a key role. The present study was taken up to see the effect of three different sandhana dravya (fermenting agents), i.e., Dhataki pushpa (DAK), Madhuka (MAK), and yeast (YAK) on the formulation characterization of $A$. kalpa.

Results: The prepared samples were tested for their physicochemical parameters, i.e., total solid, pH, specific gravity, sugar content, alcohol content, refractive index, phytochemical screening, quantitative assay for secondary metabolites, and high-performance thin-layer chromatography (HPTLC) fingerprinting. The findings of phytochemical evaluation, quantitative assay, and HPTLC fingerprint show marked variation among three different prepared samples of A. kalpa. The preliminary phytochemical estimation for the detection of secondary metabolites was done. The study revealed the presence of highest percentage of alkaloids in YAK, tannins in DAK and saponins in YAK. Total solid content was found to the highest in MAK. Physicochemical parameters such as $\mathrm{pH}$, total solid content, refractive index, alcohol content, and specific gravity also showed marked variation. Alcohol content for the DAK and YAK was found same.

Conclusion: sandhana dravya (fermenting agent) causes variations in different physicochemical and phytochemical parameters in the formulation and development of $A$. kalpa.

Keywords: Sandhana dravya (fermenting agent), Sandhana, Ashwagandha Kalpa, High-performance thin-layer chromatography.

(C) 2017 The Authors. Publishedby Innovare Academic Sciences Pvt Ltd. This is an open access article under the CC BY license (http://creativecommons. org/licenses/by/4. 0/) DOI: http://dx.doi.org/10.22159/ajpcr.2017.v10s4.21338

\section{INTRODUCTION}

Sandhana kalpana has proven itself more beneficial as compared to other dosage form (kalpa) due to better medicinal as well as nutritive values [1,2]. Moreover, the self-generated alcohol from Sandhan Prakriya facilitates maximum extraction of active pharmaceutical ingredients from the raw drugs and also acts as a preservative $[3,4]$. Natural fermenting agent Woodfordia fruticosa (Dhataki) belongs to the Lythraceae family. W. fruticosa flowers as a constituent of Sandhana kalpa help in treating burning sensations in the stomach. As per Indian system of medicine, the flowers of this plant are pungent, acrid, uterine sedative and useful in leprosy, toothache, leucorrhea, fever, dysentery, and blood diseases. Another plant Madhuca longifolia (Mahua) belongs to family Sapotaceae. M. longifolia (Mahua) fruits are used as anti-inflammatory, antiulcer, and as hypoglycemic agents [5,6]. In the Ayurvedic Systems, the inoculum of yeasts comes from the Dhataki flowers, which contain the wild species of yeast. These flowers are nectariferous and highly tanniferous. The flowers contain the yeast spores in the dry nectariferous region [7-9]. The prepared three formulations of A. kalpa contain Ashwagandha, Vacha, Bramhi, Sarpagandha, Dhataki/Mahua/yeast, and Guda as its active ingredients. The formulation is prepared as per the method for madya Sandhana mentioned in Ayurvedic literature [10].

\section{METHODS}

The required ingredients of the formulation $A$. kalpa were procured from M/S Baijnath Pharmacy, Paprola (H.P.) subjected to quality evaluation using analytical parameters as mentioned in The Ayurvedic Pharmacopeia of India.

\section{Method of preparation of $\boldsymbol{A}$. kalpa}

After identification and quality evaluation, all the ingredients were cleaned and washed. The drugs were triturated to coarse powder. Decoction was prepared by boiling the powdered drugs (1 part) in a specified volume of water (16 parts) for a definite time (until $1 / 4^{\text {th }}$ part of water remains). After that, it was cooled and filtered. Madhur dravya (Jaggery) was added into previously prepared kwath and mixed well to get it solubilized (Table 1). Further the prepared decoction was divided into three batches (Each $6 \mathrm{~L}$ ). The fermenting agents Dhataki pushpa (75 g), Madua (75 g), and yeast (75 g) were added separately into three batches. These were transferred to Mruth patra (earthen pot) and placed under ground (Sandhana pradesha) for 45 days (Sandhana kalpa) for complete fermentation (madya sandhana). After fermentation, the solutions were taken out and filtered. The filtered solutions were kept unshaken for 15 days in order to sediment any possible solid material. The prepared batches were subjected to analytical study.

\section{Analytical study}

Organoleptic tests [11]

Organoleptic characters such as colour, odour, and taste were observed by sensory evaluation.

\section{Physicochemical parameters}

Determination of $p H$ [12]

The $\mathrm{pH}$ of the A. kalpa was determined using combined glass electrode $\mathrm{pH}$ meter as per the procedure mentioned in the Quality Standards of Indian Medicinal Plants. 
Determination of specific gravity at room temperature [13]

The specific gravity was measured using pycnometer at $25^{\circ} \mathrm{C}$ as per the procedure mentioned in the Ayurvedic Pharmacopoeia of India.

\section{Determination of total solid content [14]}

The total solid contents were determined by gravimetric method. The sample was taken in pre-weighed evaporating dish, and contents were evaporated over water bath and finally weighed.

\section{Refractive index [15]}

The refractive index of formulation was measured using Abbe's refractometer as per the procedure reported in the Pharmacopoeial Standards for Ayurvedic Formulations.

\section{Determination of alcohol content [15]}

Alcohol content was measured using alcohol distillation apparatus. The preparation $(25 \mathrm{ml})$ was transferred to the distillation flask and diluted with $250 \mathrm{ml}$ of water. $90 \mathrm{ml}$ of distillate was collected, and $100 \mathrm{ml}$ volume was made in volumetric flask by the addition of distilled water. The specific gravity was measured using pycnometer, and percentage alcohol content was calculated using Hammond's table.

\section{Qualitative tests [16-19]}

The qualitative tests were carried out for the detection of alkaloids, tannins, glycosides, steroids, carbohydrates, and amino acids as per the standard testing protocol mentioned in the reference.

\section{Quantitative evaluation}

Quantitative estimation of alkaloids [16-19]

The samples were estimated quantitatively for total alkaloid content by gravimetric method mentioned as per the standard testing protocol mentioned in the reference.

\section{Quantitative estimation of tannins [16-19]}

Tannin estimation was done by volumetric method mentioned as per the standard testing protocol mentioned in the reference.

\section{Quantitative estimation of total saponin content [16-19]}

Total saponin assay was carried out by gravimetric method reported in as per the standard testing protocol mentioned in the reference.

\section{High-performance thin-layer chromatography (HPTLC) [20-23]} Sample preparation

The sample (2 ml) was dissolved in $2 \mathrm{ml}$ mixture of chloroform and methanol $(1: 1 \mathrm{v} / \mathrm{v})$ and kept aside for few minutes. Contents were filtered through Whatman No.1. Filtrate was collected and centrifuged. The supernatant was transferred to another clean test tube for HPTLC analysis.

\section{Sample coding}

- $\quad$ Track 1 - DAK (Dhataki-based A. kalpa)

- Track 2 - MAK (Madhuka-based A. kalpa)

- Track 3 - YAK (yeast-based A. kalpa)

- Track 4 - Methanolic extract of Ashwagandha

- Track 5 - Methanolic extract of Brahmi

- Track 6 - Methanolic extract of Dhataki

- $\quad$ Track 7 - Methanolic extract of Madhuka

- Track 8 - Methanolic extract of Sarpagandha

- Track 9 - Methanolic extract of Vacha

\section{Chromatography conditions}

- Application mode: Camag Linomat V

- Development chamber: Camag twin trough chamber

- Stationary phase: Precoated silica gel GF254 plates

- Mobile phase: Chloroform:methanol (9:1 v/v)

- Chamber saturation: 30 minutes

- Development time: 30 minutes

- Development distance: $7 \mathrm{~cm}$
- Scanner: Camag scanner III

- Detection: Deuterium lamp, tungsten lamp

- Data system: winCATS Software

- Detection wavelength: 254 and $366 \mathrm{~nm}$

- Derivatizing agent: Vanillin sulfuric acid.

\section{RESULTS AND DISCUSSION}

The results for organoleptic evaluation are given in Table 2. These illustrate the comparison among the three samples of A. kalpa, i.e., DAK, MAK, and YAK prepared using three different fermenting agents, i.e., Dhataki pushpa, Madhuka pushpa, and yeast. Significant differences were observed in physicochemical characterizations (Table 3). The total solid content was found to be $15.9 \% \mathrm{w} / \mathrm{w}, 30.2 \% \mathrm{w} / \mathrm{w}$, and $11.8 \%$ $\mathrm{w} / \mathrm{w}$ in DAK, MAK, and YAK, respectively. The results reveal high value of total solid content in Madhuka used A. kalpa as compared to Dhataki and yeast. No marked difference was observed for $\mathrm{pH}$, specific gravity, and refractive index values. The results for alcohol content reveal a significant variation as the total alcohol content was found to be $8 \%$, $4 \%$, and $8 \%$ for DAK, MAK, and YAK, respectively. Alcohol percentage was found to be less in Madhuka-based A. kalpa as compared to Dhataki

Table 1: Preparation for Ashwagandha kalpa

\begin{tabular}{lll}
\hline Ingredients & Parts used & Amount used \\
\hline Ashwagandha & Root & $1200 \mathrm{~g}$ \\
Sarpagandha & Root & $900 \mathrm{~g}$ \\
Brahmi & Whole plant & $600 \mathrm{~g}$ \\
Vacha & Rhizomes & $300 \mathrm{~g}$ \\
Water & & Quality taken for kwath 160 l \\
& & Reduced to 20 l \\
Jaggery & & $1275 \mathrm{~g}$ \\
\hline
\end{tabular}

Table 2: Organoleptic character of A. kalpa

\begin{tabular}{llll}
\hline $\begin{array}{l}\text { Organoleptic } \\
\text { evaluation }\end{array}$ & Dhataki (DAK) & Madhuka (MAK) & Yeast (YAK) \\
\hline Color & Dark brown & Dark brown & Dark brown \\
Odor & Aromatic & Aromatic & Aromatic \\
Taste & Sweet & Sweet & Sweet \\
\hline
\end{tabular}

Table 3: Results of physicochemical parameters of $A$. kalpa

\begin{tabular}{llll}
\hline Parameters & DAK (D) & MAK (M) & YAK (Y) \\
\hline $\mathrm{pH}$ & 4.87 & 4.92 & 4.84 \\
Total solid content & 15.9 & 30.2 & 11.8 \\
Refractive index & 1.38 & 1.37 & 1.41 \\
Alcohol content & $8 \%$ & $4 \%$ & $8 \%$ \\
Specific gravity & 1.01 & 1.05 & 1.09 \\
\hline
\end{tabular}

Table 4: Results of phytochemical screening of $A$. kalpa

\begin{tabular}{|c|c|c|c|c|}
\hline Phytoconstituents & Test & DAK & MAK & YAK \\
\hline \multirow[t]{2}{*}{ Alkaloids } & $\begin{array}{l}\text { Dragendorff's } \\
\text { reagent }\end{array}$ & Positive & Positive & Positive \\
\hline & $\begin{array}{l}\text { Mayer's } \\
\text { reagent }\end{array}$ & Positive & Positive & Positive \\
\hline \multirow[t]{4}{*}{ Tannin } & Lead acetate & Positive & Positive & Positive \\
\hline & $\begin{array}{l}\text { Potassium } \\
\text { dichromate }\end{array}$ & Negative & Negative & Negative \\
\hline & Acetic acid & Negative & Negative & Negative \\
\hline & $\begin{array}{l}\text { Iodine } \\
\text { solution }\end{array}$ & Positive & Positive & Positive \\
\hline Carbohydrates & Fehling's test & Positive & Positive & Positive \\
\hline & Salkowski & Negative & Negative & Negative \\
\hline Saponin glycoside & Foam test & Positive & Positive & Positive \\
\hline
\end{tabular}


and yeast. Qualitative evaluation shows similar findings for all the three prepared samples (Table 4).

Quantitative assay was carried out for determination of total alkaloid, saponin, and tannin contents (Table 5). The alkaloid content was found to be $0.22 \%, 1.1 \%$, and $3 \%$ in DAK, MAK, and YAK, respectively. Yeastbased A. kalpa shows more percentage of alkaloid as compared to Dhataki and Madhuka. The content of tannins was found to be $77.7 \%$, $16.2 \%$, and $44.8 \%$ respectively in DAK, MAK, and YAK, respectively. The results show more tannin content in Dhataki and yeast-based formulation as compared to Madhuka-based formulation. When samples were analyzed for total saponin content again, significant variation was observed where the highest percentage was observed in yeast-based formulation as compared to Dhataki- and Madhuka-based formulation.

The HPTLC method described utilizes silica gel GF 254 HPTLC plates as stationary phase and chloroform:methanol (9:1 v/v) as mobile phase which gives good separation of active constituents present in three different samples of A. kalpa. Extracts of all the ingredients used in preparation were taken as botanical reference. The results reveal that all the three samples of $A$. kalpa show almost similar retention behavior on silica gel (Fig. 1a and b). The separation pattern shows the presence of chemical moieties of the respective ingredients in all the three samples of $A$. kalpa as shown in Table $6 \mathrm{a}$ and $\mathrm{b}$. When visualization was done at $254 \mathrm{~nm}$, the results show separation of 13 components in DAK, 13

Table 5: Results of quantitative estimation

\begin{tabular}{llll}
\hline Parameters & DAK (D) & MAK (M) & YAK (Y) \\
\hline Alkaloids (\%) & 0.22 & 1.1 & 3 \\
Tannin (\%) & 77.7 & 16.2 & 44.8 \\
Saponin (\%) & 1.3 & 0.69 & 6.29 \\
\hline
\end{tabular}

Table 6a: Results of HPTLC at $254 \mathrm{~nm}$

\begin{tabular}{lll}
\hline $\begin{array}{l}\text { Track } \\
\text { number }\end{array}$ & $\begin{array}{l}\text { Number } \\
\text { of spots }\end{array}$ & $\mathbf{R}_{\mathbf{f}}(\mathbf{2} \mathbf{n} \mathbf{~ n m})$ \\
\hline 1 & 13 & $\begin{array}{l}0.18,0.22,0.26,0.33,0.42,0.52,0.62,0.65, \\
0.68,0.72,0.82,0.85,0.92\end{array}$ \\
& & $\begin{array}{l}0.18,0.22,0.26,0.33,0.42,0.53,0.62,0.66, \\
0.82,0.85,0.92\end{array}$ \\
& 13 & $0.18,0.22,0.26,0.33,0.42,0.52,0.62,0.65$, \\
3 & & $0.68,0.72,0.82,0.85,0.92$ \\
4 & 14 & $0.33,0.65$ \\
5 & 2 & $0.24,0.42,0.46,0.62,0.74$ \\
6 & 5 & $0.34,0.42,0.73$ \\
7 & 3 & $0.26,0.33,0.42,0.54,0.65,0.73,0.84$ \\
8 & 7 & $0.18,0.33,0.42,0.54,0.72$ \\
9 & 5 & $0.33,0.44,0.72,0.85$ \\
\hline
\end{tabular}

HPTLC: High-performance thin-layer chromatography

Table 6b: Results of HPTLC at $366 \mathrm{~nm}$

\begin{tabular}{lll}
\hline $\begin{array}{l}\text { Track } \\
\text { number }\end{array}$ & $\begin{array}{l}\text { Number } \\
\text { of spots }\end{array}$ & $\mathbf{R}_{\mathbf{f}} \mathbf{m a x} .(366 \mathbf{n m})$ \\
\hline 1 & 7 & $0.07,0.18,0.25,0.41,0.50,0.65,0.84$ \\
2 & 8 & $0.07,0.17,0.25,0.42,0.51,0.55,0.64,0.84$ \\
3 & 7 & $0.07,0.17,0.25,0.41,0.50,0.65,0.84$ \\
4 & 2 & $9.25,0.41$ \\
5 & 1 & 0.65 \\
6 & 2 & $0.07,0.50$ \\
7 & 2 & $0.41,0.85$ \\
8 & 9 & $0.07,0.017,0.25,0.35,0.41,0.45,0.50,0.60$, \\
& & 0.74 \\
9 & 3 & $0.25,0.40,0.65$ \\
\hline
\end{tabular}

components in MAK, and 14 components in YAK. When comparison was done with a sample of raw ingredients, then all the respective chemical moieties were found to be present in formulation samples. The scanning results at $366 \mathrm{~nm}$ show separation of 7 components in DAK, 8 components in MAK, and 7 components in YAK. The reason for the appearance of less number of components at $366 \mathrm{~nm}$ may be that some of the components are not sensitive at long UV radiations. The three-dimensional desitogram shows the overlapping peaks of the common components in all the tracks (Fig. 2a and b). The HPTLC results support the qualitative evaluation.

\section{CONCLUSION}

The study was carried out to find out the impact of fermenting agents on marketed patent proprietary formulation A. kalpa. Various findings of analytical study show that the fermenting agent plays an important role in fermentation of asava and arishta. In the present study, three fermenting agents, Dhataki pushpa, Madhuka pushpa, and yeast, were used for preparing A. kalpa. The prepared samples were analyzed for their quality evaluation by physicochemical parameters, qualitative screening, quantitative assay, and HPTLC fingerprint. The results show

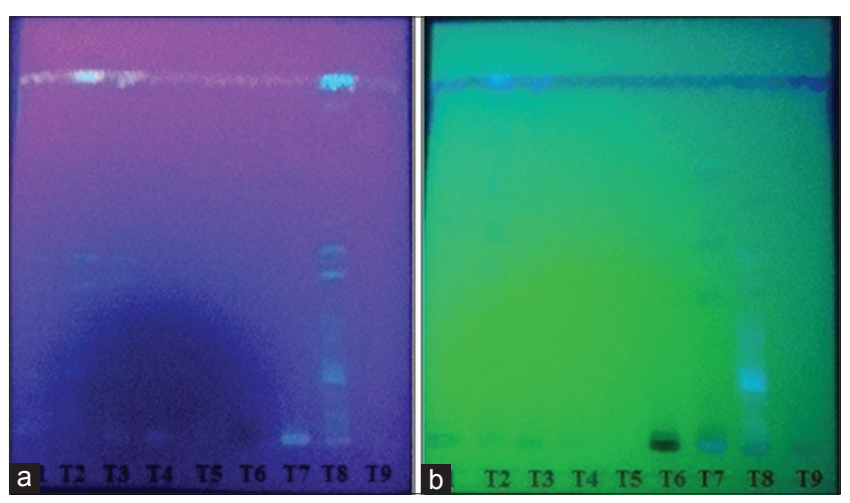

Fig. 1: (a) Thin-layer chromatography (TLC) fingerprint at $366 \mathrm{~nm}$, (b) TLC fingerprint at $254 \mathrm{~nm}$

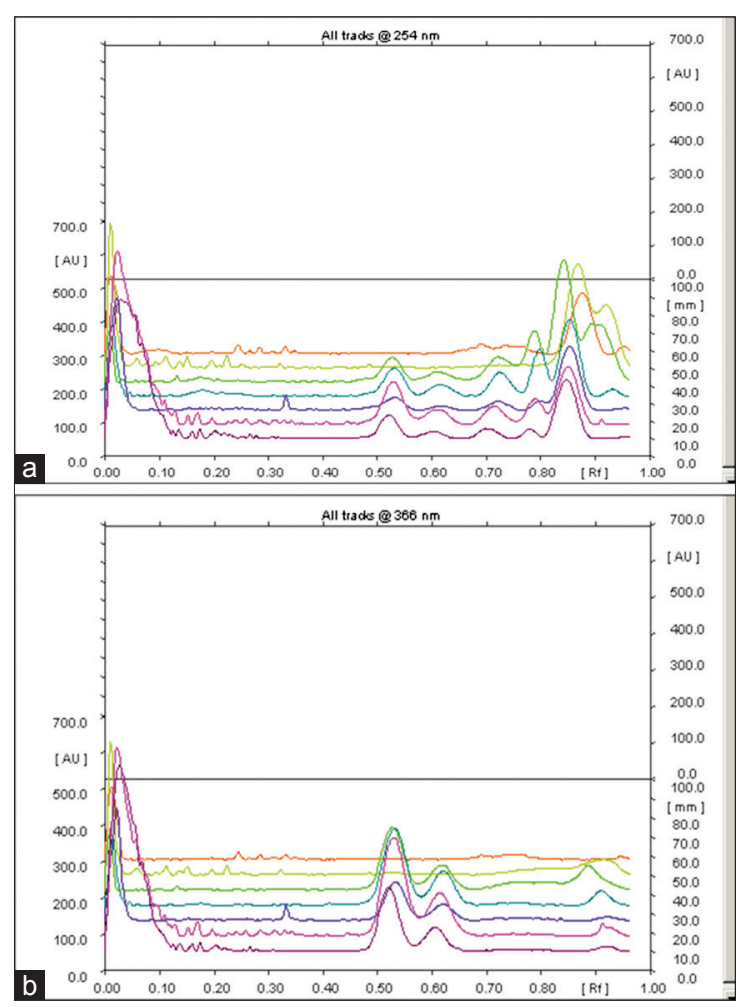

Fig. 2: 3D HPTLC desitogram shows overlay peaks of prepared A. Kalpa 
that maximum alcohol content was generated in yeast- and Dhatakibased A. kalpa. Similarly, when analysis was carried out for quantitative assay for alkaloid, tannin and saponins, the highest percentage was found in Dhataki- and yeast-based samples. Therefore, Dhataki and yeast can give better extraction of active constituents as compared to Madhuka pushpa. Based on the findings, it can be concluded that Dhataki and yeast can work as better fermenting agents when compared with Madhuka pushpa for the formulation of A. kalpa.

\section{ACKNOWLEDGMENT}

The authors are grateful to Lovely Professional University, Phagwara (PB) and M/S Baijnath Pharmacy, Paprola (H.P.) for providing the necessary infrastructure and resources to carry out this research project.

\section{REFERENCES}

1. Joshi D, Jha CB. Critical study of the asavaishta preparations of brhatirayee. Anc Sci Life 1990;9(3):125-33.

2. Chaudhary AK, Kanjiv L. Bhaishjya Ratnawali of Govinda Dasji. $1^{\text {st }}$ ed., Vol. 3. Varanasi: Chaukhambha Sanskrit Sansthana; 2006. p. 100-54, 365-70.

3. Muralidhar R, Chaudhary A, Ravishankar B, Dey S, Prajapati PK. A comparative pharmaceutico-pharmacoclinical study of different samples of Shirisharishta and its shwashara effect. AYU 2004;7:45-9.

4. Lakhani R, Chaudhary AK. A comparative pharmaceutico-clinical study on Arka Kalpana and Arishta Kalpana W.S.R. to Jirakadyarka and Jirakadyarishta on Grahani. Sachitra Ayurveda 2004;8:145-8.

5. Bajaj V, Chaudhary AK. Validation process in "Sandhan Kalpana" Sachitra. Ayurveda 2002;5:846-8.

6. Gandhi P, Chaudhary AK, Ravishankar B, Dey S, Prajapati PK. A Comparative Study of Different Formulations of Vasa (Avaleha, Sneha, Sandhan) WSR to its Swasahar Effect, MD (AY) Dissertation of IPGTRA. Jamnagar: Gujarat Ayurveda University; 2005.

7. Shastri MV. Vaidya Yoga Ratnavali. Madras: IMPCOPS; 1968. p. 6-10.

8. Vohra A, Satyanarayana T. Phytase production by the yeast Pichia anomala. Biotechnol Lett 2001;23:551-4.

9. Vohra A, Satyanarayana T. A cost-effective cane molasses medium for enhanced cell-bound phytase production by Pichia anomala. J Appl Microbiol 2004;97(3):471-6.

10. Hiremath SG, Joshi D. Role of different containers and methods on alcoholic preparations with reference to kutajarista. Anc Sci Life 1991;10(4):256-63.

11. William H. Official Method of Analysis. Washington: Association of Official Agricultural Chemists; 1960. p. 185.

12. Gupta AK, Tandan N, Sharma M. Quality Standards of Indian Medicinal Plants. Vol. 6. New Delhi: Medicinal Plants Unit, Indian Council of Medical Research; 2008. p. 290

13. Anonymous. The Ayurvedic Pharmacopoeia of India. Part-1. Vol. 1. Ministry of Health and Family Welfare, Government of India, Department of ISM \& H; 1999. p. 140-3.

14. Anonymous. Protocol for Testing of Ayurvedic, Siddha and Unani Medicines. Pharmacopoeial Laboratory for Indian Medicine, AYUSH. Ghaziabad: Ministry of Health and Family Welfare, Government of India; 2011.

15. Ministry of Health and Family Welfare, Government of India. Pharmacopoeial Standards for Ayurvedic Formulations CCRAS. New Delhi: Ministry of Health and Family Welfare, Government of India; 1987.

16. Shankar R. Text Book of Pharmaceutical Analysis. Otacamund: Rx Publication; 2001

17. Baxi AJ, Shukla VJ, Bhatt UB. Methods of Qualitative Testing of some Ayurvedic Formulation. Jamnagar: Gujarat Ayurved University; 2001.

18. Mendham J, Denney RC, Barnes JD, Thomas MJ. Vogel's Text Book of Quantitative Chemical Analysis. $6^{\text {th }}$ ed. Essex: Pearson Education Asia; 2002.

19. Anonymous. Quality Standard of Indian Medicine Plants. Vol. 2. New Delhi: Indian Council of Medical Research; 2005.

20. Kasture AV, Wadodkar SG, Mahadik KR, More HN. Industrial methods. Pharmaceutical Analysis. Vol. 2. Pune: Nirali Prakashan; 2008.

21. Anonymous. Planner chromatography. Modern Thin Layer Chromatography. Switzerland: CAMAG Muttenz; 1999. p. 2-16.

22. Chahal MK, Ydav PK, Bumbrah GS, Sharma RM. Thin layer chromatographic analysis of some common over the counter (OTC) cough-cold preparations. Egypt J Forensic Sci 2016;6:351-60.

23. Stahl E. Thin-Layer-Chromatography: A Laboratory Hand Book. Translated by Ashworth MR. $2^{\text {nd }}$ ed. Berlin, Heidelberg, New York: Spring-Verag; 1969. 